\title{
Five-year results of photodynamic therapy with verteporfin for Japanese patients with neovascular age-related macular degeneration
}

This article was published in the following Dove Press journal:

Clinical Ophthalmology

26 March 2013

Number of times this article has been viewed

\section{Takashi Tsuchihashi \\ Keisuke Mori \\ Kazuhiro Ueyama \\ Shin Yoneya}

Department of Ophthalmology, Saitama Medical University, Iruma, Saitama, Japan
Correspondence: Keisuke Mori Department of Ophthalmology, Saitama Medical University 38 Morohongo, Moroyama, Iruma, Saitama, 350-0495, Japan

$\mathrm{Tel}+8 \mid 49276$ I 250

$\mathrm{Fax}+81492958002$

Email keisuke@saitama-med.ac.jp
Purpose: To describe the treatment outcome of photodynamic therapy (PDT) in Japanese patients with age-related macular degeneration (AMD) followed for 5 years.

Patients and methods: We retrospectively reviewed clinical charts of 51 patients with AMD. Thirty-one eyes of typical AMD (tAMD) and 20 eyes of polypoidal choroidal vasculopathy (PCV) were evaluated.

Results: The mean logarithm of the minimum angle of resolution ( $\log M A R)$ vision of all AMD patients was 0.807 at the baseline examination and 0.937 at the 5 year examination. Mean visual acuity letter score loss is similar between patients with tAMD (-7.25) and with PCV (-5.36) at the month 60 examination. The patients with lesions of classic choroidal neovascularization (CNV) had 10.0 letters loss, but the patients with lesions of occult CNV had only 1.43 letters loss. The number of retreatments peaked in year 1 and declined immediately for patients with tAMD, but patients with PCV had significantly more frequent retreatments in the years 3 and 4 than patients with tAMD $\left(P=1.48 \times 10^{-2}, 5.96 \times 10^{-3}\right.$, respectively $)$.

Conclusion: Visual outcomes in patients with Japanese patients with AMD treated with PDT after 5-year follow up were worse than that in short-term follow up reported previously. In addition, the difference in visual prognosis between tAMD and PCV was not demonstrated after long-term follow-up.

Keywords: photodynamic therapy, age-related macular degeneration, polypoidal choroidal vasculopathy, visual outcomes

\section{Introduction}

Age-related macular degeneration (AMD) is the leading cause of severe visual loss in people over 50 years of age. ${ }^{1}$ Photodynamic therapy (PDT) with verteporfin (Visudyne, Novartis Pharmaceutical Corporation, East Hanover, NJ, USA) is approved in more than 75 countries and commonly used to treat patients with subfoveal choroidal neovascularization (CNV) associated with AMD. ${ }^{2-4}$ Several clinical trials in the United States and European countries have reported the benefits of PDT., ${ }^{2,3-9}$ Guidelines for verteporfin therapy were based on the results of these trials in predominantly Caucasian populations. Although Treatment of Age-related Macular Degeneration with Photodynamic Therapy ${ }^{5}$ (TAP) investigation reported a benefit at 24 months with respect to reducing the risk of three or more lines of visual acuity (VA) loss compared with placebo controls, the Japanese Age-Related Macular Degeneration Trial (JAT) study group ${ }^{4}$ reported that PDT for CNV in. Sixty-four Japanese patients appeared to have better angiographic and visual outcomes than those of the Western trials., ${ }^{2,3,5-9}$

Polypoidal choroidal vasculopathy $(\mathrm{PCV})$ is a distinct form of AMD, which meets the late age-related maculopathy (ARM) criteria of the International ARM 
Epidemiological Study Group, ${ }^{10}$ but the phenotypic characteristics differ from typical neovascular AMD (tAMD). Over the past decade, the spectrum of neovascular AMD has been expanded to include PCV. ${ }^{11-14}$ Patients with AMD in Japan have been reported to have PCV lesions more frequently than Caucasian patients ${ }^{15-18}$ and PDT provides favorable results in the treatment of PCV. ${ }^{19-23}$ Considering these outcomes of PDT treatments for PCV better outcomes are presumed for Japanese patients than Caucasian patients. Therefore, it is possible there may be a different response to PDT among different populations. Although TAP study provided the outcomes after PDT with AMD in the 5-year follow-up, JAT study ${ }^{4}$ and JAT extension ${ }^{24}$ have described up to 2 years follow-up information.

The purpose of this study is to provide the long-term follow-up information (5 years) after PDT in Japanese patients, and to compare the results with those of Western studies. We also explored whether the effect of PDT is different between patients with PCV lesion and those without.

\section{Materials and methods}

\section{Subjects, examination and diagnosis}

This retrospective study was conducted at Saitama Medical University, Saitama, Japan. All study subjects were unrelated Japanese Asian. All participants underwent a comprehensive ocular examination, including slitlamp biomicroscopy, funduscopy, contact lens biomicroscopic examinations of the retina, fluorescein and indocyanine green angiography, and optical coherence tomography (OCT) observation (Cirrus and Stratus, Carl Zeiss Meditec AG, Jena, Germany) at baseline and every 3-month visit. Every patient had fluorescein angiography at baseline. Regarding indocyanine green angiography, there were five exceptions, with a history of allergy for iodide, a positive result on pre-injection test or a known systemic problem such as liver disease, ischemic heart disease, cardiac arrhythmia or cardiac pacemakers. The differential diagnosis of tAMD and PCV was conducted so that if the polypoidal structure of the choroidal vessels with or without abnormal vascular networks was observed on indocyanine green angiography at the corresponding lesion on fluorescein angiography, the eyes were diagnosed as having PCV. We referred to the five cases without indocyanine green angiography, funduscopic appearance of typical orange-like polypoidal structure and OCT findings to make an accurate diagnosis.

Fifty-one consecutive patients who underwent initially PDT with the diagnosis of AMD between July 2004 and June 2005, with the completion of the month 60 examination, were recruited for this study. Inclusion criteria were as follows; (1) age of 50 years or older, (2) diagnosis of AMD in one or both eyes, (3) no association with other retinochoroidal diseases such as angioid streaks, high myopia (greater than 6D of myopic refractive error), central serous chorioretinopathy, presumed ocular histoplasmosis or retinal angiomatous proliferation (type 3 choroidal neovascularization). Excluded were the patients who had the treatments before and during the 5-year follow-ups with other methodologies; antivascular endothelial growth factor therapies, thermal laser photocoagulation, transpupillary thermotherapy, and/or vitreous surgery.

The main outcome of this study was best corrected visual acuity (BCVA) alteration during 5-year follow-up. We also analyzed the number of PDT retreatments. Recurrence of AMD was determined by a significant increase $(20 \%$ or more compared with the lowest measurement at any previous scheduled visit) of the retinal thickness due to retinal edema and retinal detachment delineated by OCT measurement, increased or persistent fluorescein leakage from CNV or appearance of new retinal hemorrhage of one disc diameter or greater after 3 months or more. Additional retreatments were given if the CNV recurrence was observed as often as every 3 months during the 5 -year follow-up.

\section{Treatment procedures}

The treatment protocol followed that used in the JAT study. ${ }^{4}$ Treatment involved a 10 minute intravenous infusion of verteporfin, $6 \mathrm{mg} / \mathrm{m}^{2}$ body surface area, followed by light exposure 15 minutes after the start of the infusion. Light exposure was given with a diode laser beam $(639 \pm 3 \mathrm{~nm})$, delivered at $600 \mathrm{~mW} / \mathrm{cm}^{2}$ for 83 seconds to produce $50 \mathrm{~J} / \mathrm{cm}^{2}$.

\section{Statistical analysis}

The BCVA was determined using the Landolt $\mathrm{C}$ chart, and was calculated and presented as the logarithm of the minimum angle of resolution (logMAR) for statistical analyses and for conversion to letter scores. The following calculations were used:

- $\log$ MAR value $=\log 10$ (1/VA using Landolt $\mathrm{C}$ chart $)$.

- Each 0.10 unit of $\log$ MAR difference = 5 letters.

The measured mean value of each group was compared using paired or unpaired $t$-test, chi-square test, and Bonferroni multiple comparison correction. $P<0.05$ was considered to be statistically significant. All analysis was performed with commercially available software (SSRI version. 1.20, SSRI, Tokyo, Japan). 


\section{Results}

\section{Patient characteristics}

Of the 51 exudative AMD patients, 31 patients (61\%) were diagnosed with tAMD, and the remaining 20 patients (39\%) were diagnosed with PCV. The baseline characteristics of study participants are summarized in Table 1. At baseline, the distribution of age, gender, great linear dimension (GLD), $\log$ MAR vision and central retinal thickness were not significantly different between tAMD and PCV $(P>0.05)$ patients. However, patients with tAMD had classic lesions more frequently than patients with PCV $\left(P=7.81 \times 10^{-4}\right)$.

\section{Visual outcomes}

The mean $\log$ MAR vision in all AMD patients was 0.807 (corresponding approximate VA score: 0.15 ) at the baseline examination and 0.937 (corresponding approximate visual acuity score: 0.11 ) at the month 60 examination. The logMAR vision gradually decreased throughout the follow-up period, but the difference between baseline and month 60 was not significant in each subset group (tAMD; $P=0.110$, PCV; $P=0.290$, all AMD; $P=0.052$ ) (Figure 1).

Mean $\log$ MAR vision loss was similar between patients with tAMD and with PCV. The significant difference was not demonstrated in the change of logMAR vision from baseline between tAMD and PCV throughout the follow-up period ( $P=0.814$ at month 6, 0.957 at month $12,0.544$ at month 24 and 0.781 at month 60 ). LogMAR vision of patients with occult CNV improved from $0.822 \pm 0.419$ at baseline to $0.781 \pm 0.516$ at month 24 while $\log$ MAR vision of patients with classic $\mathrm{CNV}$ worsened from $0.796 \pm 0.311$ at baseline to $0.884 \pm 0.473$ at month 24 . However, the significant difference was not seen between these patient groups throughout the follow up ( $P=0.097$ at month $6, P=0.518$ at month $12, P=0.595$ at month 24 and $P=0.197$ at month 60 ).
Figure 2 demonstrates mean change in letters from baseline ( $\log$ MAR vision converted to visual acuity letter scores) throughout 60-month follow up for all patients with AMD, tAMD and PCV (Figure 2A) and for 30 patients with classic $\mathrm{CNV}$ and 21 patients with occult CNV (Figure 2B). Mean visual acuity letter score decreased 6.51 in patients with all AMD, 7.25 in patients with tAMD and 5.36 in patients with $\mathrm{PCV}$ at the month 60 examination (Figure 2A). The patients with lesions of predominantly or minimally classic $\mathrm{CNV}$ had 10.0 letters loss, but the patients with lesions of occult with no classic CNV had only 1.43 letters loss (Figure 2B).

\section{Number of retreatments}

The mean number of retreatments per year during the follow up period is shown in Table 2. The number of retreatments peaked in year 1 and declined along the time course for patients with tAMD, but patients with PCV had significantly more frequent retreatments in the years 3 and 4 than patients with tAMD $\left(P=1.48 \times 10^{-2}, 5.96 \times 10^{-3}\right.$, respectively $)$.

\section{Discussion}

A previous randomized clinical trial for Japanese AMD (JAT study) provided 1-year results of PDT, demonstrating better angiographic and vision effects to those observed in Caucasian patients. ${ }^{4}$ JAT extension study showed similar favorable results through 2-year follow up. Mean visual acuity letter score in the study eye increased from 50.8 at baseline to 54.0 at month 24. In contrast to those reports, the mean $\log M A R$ vision in all AMD patients decreased from 0.807 (corresponding approximate visual acuity score: 0.15 ) at the baseline to 0.937 (corresponding approximate visual acuity score: 0.11 ) at the month 60 examination. Although many previous reports, with up to 12 months follow up results, described favorable results of PDT in treating PCV, ${ }^{19-23}$ our data did not show the significant

Table I Baseline characteristics of study participants

\begin{tabular}{|c|c|c|c|}
\hline & tAMD & PCV & $P$ \\
\hline Number of patients & 31 & 20 & \\
\hline Age (mean $\pm S D)$ & $70.3 \pm 7.2$ & $69.5 \pm 7.5$ & $0.686 *$ \\
\hline Sex (male/female) & $24 / 7$ & $16 / 4$ & $0.826^{\dagger}$ \\
\hline Angiographic classification (classic/occult) ${ }^{\ddagger}$ & $24 / 7$ & $6 / 14$ & $7.81 \times 10^{-4 \dagger}$ \\
\hline GLD $(\mu \mathrm{m}$, mean $\pm \mathrm{SD})$ & $3172 \pm 1352$ & $3550 \pm 1321$ & $0.834 *$ \\
\hline Mean BCVA, logMAR vision (mean $\pm S D$ ) & $0.85 \pm 0.33$ & $0.73 \pm 0.40$ & $0.141 *$ \\
\hline $\begin{array}{l}\text { Mean BCVA, corresponding approximate } \\
\text { decimal visual acuity }\end{array}$ & 0.141 & 0.186 & \\
\hline Mean CRT $(\mu \mathrm{m}$, mean $\pm \mathrm{SD})$ & $489 \pm 143$ & $54 I \pm 195$ & $0.815^{*}$ \\
\hline
\end{tabular}

Notes: *Unpaired $t$-test; ${ }^{\dagger}$ Chi-square test; ffluorescein angiographic classification, classic indicates patients with lesions composed of predominantly or minimally classic CNV and occult indicates patients with lesions composed of occult with no classic choroidal neovascularization (CNV).

Abbreviations: tAMD, typical neovascular age-related macular degeneration; PCV, polypoidal choroidal vasculopathy; SD, standard deviation; GLD, greatest linear dimension; BCVA, best corrected visual acuity; logMAR, logarithm of minimum angular resolution; CRT, central retinal thickness. 
1.2

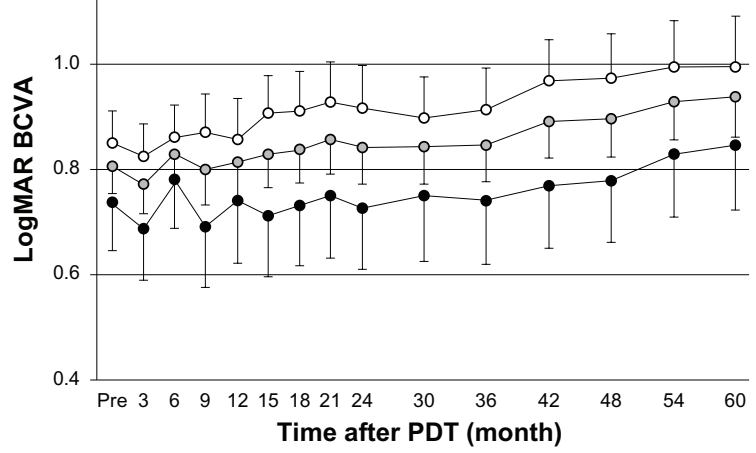

Figure I Best corrected visual acuity (BCVA) for all neovascular age-related macular degeneration (AMD), typical neovascular AMD (tAMD) and polypoidal choroidal vasculopathy (PCV) patients after photodynamic therapy (PDT) (open circles, tAMD; gray circles, all AMD; solid circles, PCV) over the 60 month follow-up period.

Notes: The BCVA was determined using the Landolt $C$ chart, and was calculated and presented as the logarithm of the minimum angle of resolution (logMAR). Values are presented as mean. (Error bar and standard error).

Abbreviation: PDT, photodynamic therapy.

difference in visual prognosis between tAMD and PCV after long-term follow-up. Mean visual acuity letter score loss is similar between patients with $\mathrm{AAMD}$ and with $\mathrm{PCV}$ at the month 60 examination with no significant difference. These facts suggest that the better results in Japanese AMD patients and predominance of PCV in the visual outcome may be temporal during the first 2 years and may not last for more than 5 years.

Interestingly, this study demonstrated that the patients with lesions of classic CNV had 10.0 letters loss, while the patients with lesions of occult $\mathrm{CNV}$ had only 1.43 letters

A

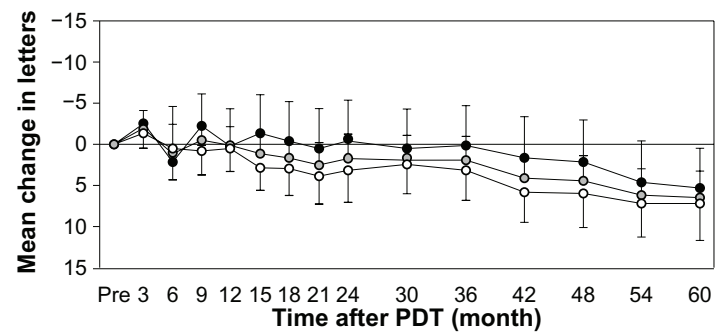

B

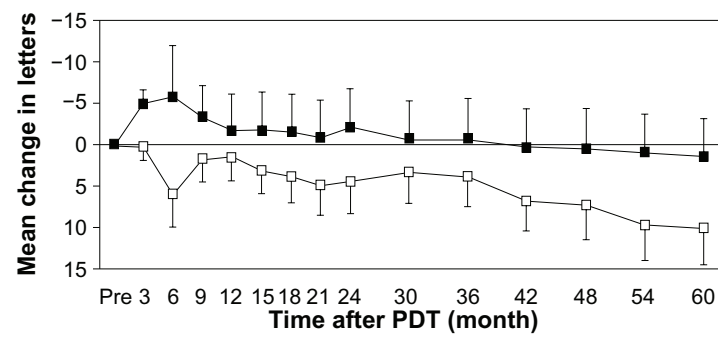

Figure 2 Mean change in letters from baseline for all long-term verteporfin treated patients; (A) open circles, tAMD; gray circles, all AMD; solid circles, PCV, (B) open squares, the patients with classic CNV; solid squares, the patients with occult CNV. Note: (Error bar and standard error).

Abbreviation: PDT, photodynamic therapy; tAMD, typical neovascular; AMD, agerelated macular degeneration; PCV, polypoidal choroidal vasculopathy; CNV, choroidal neonvascularization.
Table 2 Mean number of retreatments

\begin{tabular}{llll}
\hline & \multicolumn{4}{l}{$\begin{array}{l}\text { Number of retreatments during each yearly } \\
\text { period (mean } \pm \text { SD) }\end{array}$} \\
\cline { 2 - 4 } & tAMD & PCV & $\boldsymbol{P}$ \\
\hline Year I & $0.55 \pm 0.72$ & $0.35 \pm 0.48$ & 0.286 \\
Year 2 & $0.16 \pm 0.37$ & $0.25 \pm 0.44$ & 0.446 \\
Year 3 & $0.10 \pm 0.30$ & $0.45 \pm 0.68$ & $1.48 \times 10^{-2 *}$ \\
Year 4 & $0.03 \pm 0.18$ & $0.30 \pm 0.47$ & $5.96 \times 10^{-3 *}$ \\
Year 5 & $0.03 \pm 0.18$ & $0.10 \pm 0.31$ & 0.325 \\
\hline
\end{tabular}

Note: *Significant (unpaired $t$-test).

Abbreviations: AMD, age-related macular degeneration; tAMD, typical neovascular AMD; PCV, polypoidal choroidal vasculopathy; SD, standard deviation.

loss in 5 years. Patients with occult CNV gained 5.81 letters at month 6 and 2.07 at month 24 while patients with classic CNV lost 5.96 letters at month 6 and 4.39 at month 24 . However, the significant difference was not seen between these a patient groups throughout the follow up. Figure 3 provides a comparative summary of visual outcomes of our study and the TAP investigation., ${ }^{2,525}$ There were smaller proportions of patients who had at least a 15-letter loss in patients with occult $\mathrm{CNV}$ when compared to those with classic CNV.

The number of retreatments peaked in year 1 and declined along the time course for patients with tAMD, but patients with PCV had significantly more frequent retreatments in the years 3 and 4 than patients with tAMD $\left(P=1.48 \times 10^{-2}\right.$, $P=5.96 \times 10^{-3}$, respectively). Honda et al also described 30-month results of PDT for Japanese patients with tAMD and PCV. ${ }^{26}$ They found that recurrence of lesions in the PCV patients was more frequent than of that with the tAMD patients during the12-30 months after initial PDT, while the recurrence rate was lower in the PCV group during the first 12 months. Our finding is consistent to this report. The higher incidence of recurrence in PCV patients in the years 3 and 4 may explain

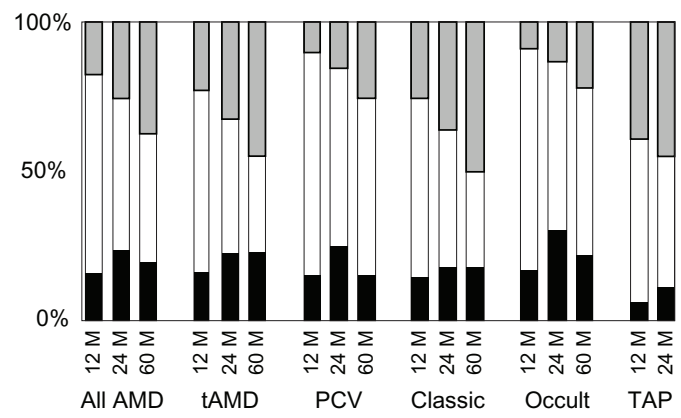

Figure 3 Comparison of visual outcomes for all patients at month 12, 24 and 60 with those of Treatment of Age-related Macular Degeneration with Photodynamic Therapy (TAP) Investigation. ${ }^{2,5,25}$

Notes: Black bars: $\geq \mid$ 5-letters increase; white bars: no change ( \pm I4 letters); gray bars: $\geq 15$-letters decrease.

Abbreviations: AMD, age-related macular degeneration; tAMD, typical age-related macular degeneration; PCV, polypoidal choroidal vasculopathy; TAP, treatment of age-related macular degeneration with photodynamic therapy study. 
predominance of $\mathrm{PCV}$ in the visual outcome is temporal during the initial 2 years and does not last for more than 5 years.

There are at least two limitations to this study. One is the small sample size, which may be associated with low statistical power, which may or may not be a reason of no significant change in VA from baseline or no significant difference in VA between tAMD and PCV detected at any time point over 5-years of follow-up. The second is that the retrospective nature of the study might exclude the patients with excellent or bad courses that could cause bias in the results. Since several antivascular endothelial growth factor drugs other than PDT are currently available and have become the first-choice treatment for AMD, it might be difficult to overcome these limitations with a single report. However, meta-analysis with an accumulation of similar data with multiple publications may be one alternative measure for these limitations, and is warranted.

\section{Acknowledgement}

This research was supported in part by an Institutional Grant (20-1-2-02) from the Medical Research Center, Saitama Medical University (KM), a grant from the Eye Research Foundation for the Aged (KM) and a grant-inaid for scientific research (21592242) from the Ministry of Education, Culture and Science in Japan (KM).

The sponsor or funding organization had no role in the design or conduct of this research.

\section{Disclosure}

The authors report no conflicts of interest in this work.

\section{References}

1. Vingerling LR, Diclemans IJ, Hofman A, et al. The prevalence of age related maculopathy in Rotterdam study. Ophthalmology. 1995;102: 205-210.

2. Treatment of age-related macular degeneration with photodynamic therapy (TAP) Study Group. Photodynamic therapy of subfoveal choroidal neovascularization in age-related macular degeneration with verteporfin: one-year results of 2 randomized clinical trials-TAP report. Arch Ophthalmol. 1999;117:1329-1345.

3. Verteporfin in Photodynamic Therapy (VIP) Study Group. Verteporfin therapy of subfoveal choroidal neovascularization in age-related macular degeneration: two-year results of a randomized clinical trial including lesions with occult with no classic choroidal neovascularization-verteporfin in photodynamic therapy report 2. Am J Ophthalmol. 2001;131:541-560.

4. Japanese Age-Related Macular Degeneration Trials (JAT) Study Group. Japanese age-related macular degeneration trial: 1-year results of photodynamic therapy with verteporfin in Japanese patients with subfoveal choroidal neovascularization secondary to age-related macular degeneration. Am J Ophthalmol. 2003;135:1049-1061.

5. Treatment of age-related macular degeneration with photodynamic therapy (TAP) Study Group. Photodynamic therapy of subfoveal choroidal neovascularization in age-related macular degeneration with verteporfin: two-year results of 2 randomized clinical trials-TAP report 2. Arch Ophthalmol. 2001;119:198-207.
6. Verteporfin in Photodynamic Therapy Study Group. Photodynamic therapy of subfoveal choroidal neovascularization in pathologic myopia with verteporfin. 1-year results of a randomized clinical trial-VIP report no 1. Ophthalmology. 2001;108:841-852.

7. Blinder KJ, Bradley S, Bressler NM, et al. Treatment of Age-related Macular Degeneration with Photodynamic Therapy study group; Verteporfin in Photodynamic Therapy study group. Effect of lesion size, visual acuity, and lesion composition on visual acuity change with and without verteporfin therapy for choroidal neovascularization secondary to age-related macular degeneration: TAP and VIP report no 1. Am J Ophthalmol. 2003;136:407-418.

8. Barbazetto I, Burdan A, Bressler NM, et al. Treatment of AgeRelated Macular Degeneration with Photodynamic Therapy Study Group; Verteporfin in Photodynamic Therapy Study Group. Photodynamic therapy of subfoveal choroidal neovascularization with verteporfin: fluorescein angiographic guidelines for evaluation and treatment-TAP and VIP report no 2. Arch Ophthalmol. 2003;121: 1253-1268.

9. Arnold JI, Blinder KJ, Bressler NM, et al. Treatment of Age-related Macular Degeneration with Photodynamic Therapy study group; Verteporfin in Photodynamic Therapy study group. Acute severe visual acuity decrease after photodynamic therapy with verteporfin: case reports from randomized clinical trials-TAP and VIP report no 3. Am J Ophthalmol. 2004;137:683-696.

10. Bird AC, Bressler NM, Bressler SB, et al. An international classification and grading system for age-related macular degeneration. The International ARM Epidemiological Study Group. Surv Ophthalmol. 1995;39:367-374.

11. Spaide RF, Yannuzzi LA, Slakter JS, Sorenson J, Orlach DA. Indocyanine green videoangiography of idiopathic polypoidal choroidal vasculopathy. Retina. 1995;15:100-110.

12. Yannuzzi LA, Ciardella A, Spaide RF, Rabb M, Freund KB, Orlock DA. The expanding clinical spectrum of idiopathic polypoidal choroidal vasculopathy. Arch Ophthalmol. 1997;115:478-485.

13. Yannuzzi LA, Wong DWK, Storzolini BS, et al. Polypoidal choroidal vasculopathy and neovascularized age-related macular degeneration. Arch Ophthalmol. 1999;117:1503-1510.

14. Ciardella AP, Donsoff IM, Huang SJ, Costa DL, Yannuzzi LA. Polypoidal choroidal vasculopathy. Surv Ophthalmol. 2004;49:25-37.

15. Sho K, Takahashi K, Yamada H, et al. Polypoidal choroidal vasculopathy: incidence, demographic features, and clinical characteristics. Arch Ophthalmol. 2003;121:1392-1396.

16. Yuzawa M, Mori R, Kawamura A. The origins of polypoidal choroidal vasculopathy. Br J Ophthalmol. 2005;89:602-607.

17. Maruko I, Iida T, Ssito M, Nagayama D, Saito K. Clinical characteristics of exudative age-related macular degeneration in Japanese patients. Am J Ophthalmol. 2005;144:15-22.

18. Mori K, Horie-inoue K, Gerhlbach PL, et al. Phenotype and genotype characteristics of age-related macular degeneration in Japanese population. Ophthalmology. 2010;117:928-938.

19. Spaide RF, Donsoff I, Lam DL, et al. Treatment of polypoidal choroidal vasculopathy with photodynamic therapy. Retina. 2002;22: 529-535.

20. Quaranta M, Maget-Faysse M, Coscas G. Exudative idiopathic polypoidal choroidal vasculopathy and photodynamic therapy with verteporfin. Am J Ophthalmol. 2002;134:277-280.

21. Chan WM, Lam DS, Lai TY, et al. Photodynamic therapy with verteporfin for symptomatic polypoidal choroidal vasculopathy. One-year results of a prospective case series. Ophthalmology. 2004; 111:1576-1584.

22. Lee SC, Seong YS, Kim SS, Koh HJ, Kwon OW. Photodynamic therapy with verteporfin for polypoidal choroidal vasculopathy of the macula. Ophthalmologica. 2004;218:193-201.

23. Silva Rm, Figueira J, Cachulo ML, Duarte L, Faria de Abreu JR, Cunha-Vaz JG. Polypoidal choroidal vasculopathy and photodynamic therapy with verteporfin. Graefes Arch Clin Exp Ophthalmol. 2005;243:973-979. 
24. Japanese Age-Related Macular Degeneration Trials (JAT) Study Group. Photodynamic therapy with verteporfin in Japanese patients with subfoveal choroidal neovascularization secondary to age-related macular degeneration (AMD): results of the Japanese AMD Trial (JAT) extension. Jpn J Ophthalmol. 2008;52:99-107.

25. Treatment of Age-Related Macular Degeneration with Photodynamic therapy (TAP) Study Group. Verteporfin therapy for subfoveal choroidal neovascularization in age-related macular degeneration: 5-year results of an open-label extension of 2 randomized clinical trials-TAP report no 8. Graefes Arch Clin Exp Ophthalmol. 2006;244:1132-1142.
26. Honda S, Kurimoto Y, Kagotani Y, Yamamoto H, Takagi H, Uenishi M. Hyogo Macular Disease Study Group. Photodynamic therapy for typical age-related macular degeneration and polypoidal choroidal vasculopathy: a 30-month multicenter study in Hyogo, Japan. Jpn J Ophthalmol. 2009;53:593-597.

\section{Publish your work in this journal}

Clinical Ophthalmology is an international, peer-reviewed journal covering all subspecialties within ophthalmology. Key topics include: Optometry; Visual science; Pharmacology and drug therapy in eye diseases; Basic Sciences; Primary and Secondary eye care; Patient Safety and Quality of Care Improvements. This journal is indexed on

\section{Dovepress}

PubMed Central and CAS, and is the official journal of The Society of Clinical Ophthalmology (SCO). The manuscript management system is completely online and includes a very quick and fair peer-review system, which is all easy to use. Visit http://www.dovepress.com/ testimonials.php to read real quotes from published authors. 